Sharif University of Technology
Scientia Iranica
Transactions A: Civil Engineering
IRAENTIA
IRttp://scientiairanica.sharif.edu

\title{
Bayesian updating of the Park-Ang damage index for RC frame buildings under near-fault ground motions
}

\author{
K. Yazdannejad and A. Yazdani* \\ Department of Civil Engineering, University of Kurdistan, Sanandaj, P.O. Box 416, Iran.
}

Received 21 January 2016; received in revised form 8 July 2016; accepted 29 October 2016

\author{
KEYWORDS \\ Damage index; \\ Bayesian approach; \\ Final period; \\ RC buildings; \\ Near-fault earthquake.
}

\begin{abstract}
A procedure for updating the Park-Ang damage index of reinforced concrete building under near-fault ground motion is proposed. Rather than developing a new damage model, a correction term is added to the existing damage model within the Bayesian framework. The correction term is described as a linear function of the variation of stiffness of structures, which is a more consistent indicator of predicting the level of damage. The Bayesian method is an effective approach when new data become available. The reinforced concrete building damage data during past near-fault pulse-like earthquakes were used in updating the damage model. The proposed damage index is conceptually simple and realistic.
\end{abstract}

(C) 2018 Sharif University of Technology. All rights reserved.

\section{Introduction}

In the repercussions of an earthquake ground motion, building damage and collapse might occur over a vast area. These buildings must be properly evaluated for structural safety [1]. Estimation of the damage of the structures is an essential requirement in performancebased structural analysis. In order to better understand the performance of structures, a comprehensive criterion with the ability to predict damage level to the structure subjected to earthquake excitation should be developed. To achieve this goal, Damage Index (DI) was introduced and different models were defined in previous studies [2-4]. DI has been increasingly accepted as a powerful tool for quantitative evaluation of structural damage caused by earthquakes. In seismic regions, damage indices have a fundamental role in decision-making about retrofit [5].

\footnotetext{
*. Corresponding author. Tel.: +98 8733668457 ;

Fax: +988733660073

E-mail address: a.yazdani@uok.ac.ir (A. Yazdani)
}

Different damage indices usually use particular parameters based on the maximum response, hysteretic energy, or structural deterioration to define damage measures [6]. In addition to the value of the deformation or energy response, the number of load cycles plays an important role in the range of damage $[7,8]$. Therefore, in estimating the damage of structures under earthquake excitations, cumulative damage models are superior to non-cumulative ones [5]. Banon and Veneziano [9] introduced a DI using the ratio of the sum of inelastic rotations during half cycles to the yield rotation. Banon et al. [10], Roufaiel and Meyer [11], and Ghobarah et al. [12] employed a concept based on the change in stiffness or flexibility for this purpose. Plastic deformation can greatly affect structural damage. Thus, the ratio of maximum plastic deformation to plastic deformation capacity was used as another parameter in determining the damage measure [13]. Hysteretic energy that merges the amount of response into the number of load cycles is a potential parameter for expressing structural damage [5,8]. Fajfar [14] and Padilla and Rodriguez [15] introduced the ratio of the hysteretic energy demand to the absorbed energy capacity of a structure under monotonic loading to 
estimate damage. Park and Ang [3] took into account both hysteretic energy and deformation to present a damage model. Some researchers have attempted to improve this model [16-18], but the original ParkAng model is still widely used in structural damage analysis [19-21]. In order to numerically calculate damage indices, the correlation between performance levels and values of damage index has been studied [22].

The mentioned damage models are deterministic and show uncertain biases and errors. In engineering studies, the nature of uncertainties is classified into inherent variability and statistical and modeling uncertainties. In general, the uncertainty due to inherent variability is quantified by probability distribution estimated from observed data, while statistical uncertainty refers to the uncertainty due to shortage of the data [23]. Model uncertainties might occur when some of the variables are removed from mathematical model for ease or are lost due to lack of knowledge [24]. Bayesian methods have been successfully employed by several studies to provide a probable solution to different engineering problems [25]. Bayesian analysis prepares a framework to incorporate all types of uncertainties into the analysis [23]. Bayesian procedures in structural damage analysis include the formal combination of priori beliefs regarding the damage with the observed data to produce an updated belief through the application of Bayes's theorem. Bayes's theorem can be achieved from the basic principles of probability theory, and it relates the probability of a proposition given the observed evidence [26]. The prior distribution is our knowledge in the Bayesian updating procedure. The information about both the prior distribution and its likelihood is combined to make the posterior distribution. This combination effectively removes the influence of statistical fluctuations and greatly improves estimation, which is close to the true distribution [27].

Considerable damage in structures was observed in the near-fault ground motions. Near-fault ground motions may be distinguished by a short duration impulsive excitation that subjects structures to higher input energy at the beginning of the record. This pulselike motion causes most of the seismic energy to arrive at the site within a short time. This situation might be particularly hazardous for structural engineering applications if it is not properly considered [28]. Therefore, the design of structures that are located in the nearfault region requires special consideration [29].

This study develops a probabilistic damage model for Reinforced Concrete (RC) structures by considering the uncertainty. Whilst the Park-Ang DI is a preferred model, it was observed that it gives an incorrect estimation of the damage at its low and high values $[12,18]$. This is due to the fact that $\mathrm{DI}_{\mathrm{PA}}$ was developed using a set of ground motion time histories from around the globe, and it acts only as an average indication of damage. Therefore, the Bayesian procedure is used for updating the deterministic Park-Ang model based on the observational data obtained from near-fault pulse-like earthquakes. The Park-Ang damage index, $\mathrm{DI}_{\mathrm{PA}}$ model, is a combination of ductility and energy absorption capacity parameters. The correction term based on the ratio of initial to final periods to provide the combined effect of stiffness degradation and plastic deformation is added to the Park-Ang damage model.

\section{Bayesian updating of damage index model}

Damage Indices (DIs) are appropriate tools for quantitative assessment of the damage in structures maintained under earthquake excitation [6,7]. The probabilistic damage index is used to update the existing deterministic models. Bayesian method, which is able to combine a wide range of information including observed data and engineering ideas, is used for this updating procedure [26]. In this study, the proposed updated model DI is adopted as follows:

$$
\mathrm{DI}(\mathbf{x}, \boldsymbol{\theta}, \sigma)=\widehat{\mathrm{DI}}(\mathbf{x})+\gamma(\mathbf{x}, \boldsymbol{\theta})+\sigma \cdot \varepsilon
$$

where $\widehat{\mathrm{DI}}(\mathbf{x})$ denotes the selected deterministic damage model to be updated (corrected); $\gamma(\mathbf{x}, \boldsymbol{\theta})$ is the correction term for the bias in the selected deterministic model; variable $\mathbf{x}$ is a vector of independent basic variables such as plastic deformation, hysteretic energy, or final period of structures; $(\boldsymbol{\theta}, \sigma)$ represent a set of unknown model coefficients for fitting the model where $\sigma$ represents the standard deviation of the model error after the bias-correction. Furthermore, $\varepsilon$ is a normal random variable with zero mean and unit variance. In this case, the exact form of $\gamma(\boldsymbol{\theta}, \sigma)$ is unknown. In structural analysis, the linear form as $\sum_{m=1}^{p} \theta_{m} h_{m}(\mathbf{x})$ is usually used, where $h_{m}(x)$ is a set of suitable explanatory functions that may influence the damage of the structure [30]. In Eq. (1), model coefficients $(\boldsymbol{\theta}, \sigma)$ are estimated using the Bayesian updating procedure [30]:

$$
f(\boldsymbol{\theta}, \sigma)=\alpha L(\boldsymbol{\theta}, \sigma) P(\boldsymbol{\theta}, \sigma),
$$

where $f(\boldsymbol{\theta}, \sigma)$ denotes the posterior distribution, reflecting the updated knowledge about $(\boldsymbol{\theta}, \sigma) ; L(\boldsymbol{\theta}, \sigma)$ is the likelihood function representing the objective information on $(\boldsymbol{\theta}, \sigma)$ obtained from a collection of the observed data; $P(\boldsymbol{\theta}, \sigma)$ shows the prior distribution reflecting our last information about $(\boldsymbol{\theta}, \sigma)$ prior to obtaining the observations, and $\alpha=$ $\left[\int L(\boldsymbol{\theta}, \sigma) P(\boldsymbol{\theta}, \sigma) d \boldsymbol{\theta} d \sigma\right]^{-1}$ is a normalizing factor [26].

The prior distribution might incorporate any information concerning $(\boldsymbol{\theta}, \sigma)$ which is obtained from previous experience or engineering judgment. $L(\boldsymbol{\theta}, \sigma)$ 
represents the likelihood of observing the experimental outcome for given values of coefficients $\boldsymbol{\theta}$ and $\sigma$ [26]. Under the assumption of statistically independent tests, the normality assumption of $\varepsilon$, and $\overline{\mathrm{DI}}_{l}=\mathrm{DI}_{i}-$ $\widehat{\mathrm{DI}}\left(x_{i}\right)-\gamma\left(x_{i}, \boldsymbol{\theta}\right)$, the likelihood function takes the following form [31]:

$$
\begin{aligned}
L(\theta, \sigma) & \propto \prod_{\text {failure data }}\left\{\frac{1}{\sigma} \varphi\left[\frac{\overline{D I_{l}}}{\sigma}\right]\right\} \\
& \times \prod_{\text {lower bound data }}\left\{\Phi\left[-\frac{\overline{D I_{l}}}{\sigma}\right]\right\} \\
& \times \prod_{\text {upper bound data }}\left\{\Phi\left[\frac{\overline{D I_{l}}}{\sigma}\right]\right\},
\end{aligned}
$$

where $\mathrm{DI}_{i}$ represents the $i$ th observed value of $\mathrm{DI} ; x_{i}$ is the $i$ th outcome of the basic variables; $\varphi$ and $\Phi$ represent the Probability Distribution Function (PDF) and Cumulative Distribution Function (CDF) of the standard normal distribution, respectively [31]. The likelihood function can even use the information of lower and upper bound data in a probabilistic model. These bounds are usually neglected during model development [32]. The formulation of the likelihood function depends on the kind and form of the available data. Theoretically, posterior distribution $f(\boldsymbol{\theta}, \sigma)$ can be determined according to the calculated information of the prior distribution and likelihood function.

There are various methods for estimating the posterior mean vector and covariance matrix such as importance sampling method, bootstrap methods, and the closed-form solution. When the presence of the lower- or upper-bound data or the probabilistic model formulation does not satisfy the linearity assumption, the importance sampling method can be very effective in the estimation of the posterior statistics of $\boldsymbol{\theta}$ and $\sigma$. Gardoni [30], by using this sampling procedure, centered the density function at the maximum likelihood point to estimate the posterior mean vector of $(\boldsymbol{\theta}, \sigma)$ as follows:

$$
M_{\Theta}=\int \Theta f(\Theta) d \Theta,
$$

where $\Theta=(\boldsymbol{\theta}, \sigma)^{T}$, and the posterior covariance matrix is accounted for as follows [30]:

$$
\begin{aligned}
\sum_{\Theta \Theta} & =E\left[\Theta \Theta^{T}\right]-M_{\Theta} M^{T} \Theta \\
& =\int \Theta \Theta^{T} f(\Theta) d \Theta-M_{\Theta} M^{T} \Theta .
\end{aligned}
$$

The main challenge here is to select a suitable form for correction function $\gamma\left(x_{i}, \boldsymbol{\theta}\right)$. The functional form should be a subtle and simple representation of structural damage. Otani et al. [33] and Sozen [34] concluded that by reducing the structural stiffness during earthquake, structural damage increases. Dipasquale and Cakmak [35] used the variation in the fundamental period of the structure as a measure of the variation in the stiffness caused by the earthquake. Therefore, the period of the structure after the earthquake and a maximum period during the earthquake can be useful factors for damage estimation. Some damage models were developed based on maximum and final softening [12,35]. Maximum softening is defined based on the ratio of initial to maximum periods. The initial period is the natural period of the structure and the maximum period is defined as the greatest period of a linear system that is equivalent to the actual nonlinear system during the earthquake. However, in the computation of the maximum softening, it is necessary to have period variation during the earthquake which is difficult. For this reason, the final softening is defined based on the ratio of initial to final periods [36]. The final period is the period at the final time step of the earthquake after which the period has no significant variations. The final softening can be measured without knowing the response of structures during the earthquake, which is a great advantage compared to maximum softening. As a result, in this study, the correction term for updating the damage model is assumed to be a function of the ratio of the initial period to the final periods. Initial period $\left(T_{0}\right)$ is the fundamental period of undamaged structure, and the final period $\left(T_{f}\right)$ is the final period of the damaged structure. Thus, the correction term of the model is considered as follows:

$$
\gamma(\mathbf{x}, \boldsymbol{\theta})=\theta_{1}+\frac{T_{0}^{2}}{T_{f}^{2}} \theta_{2} .
$$

The square of the periods is dependent on the inverse of stiffness; thus, the correction term indicates the structural stiffness degradation. The initial and final stiffness of the structure can be obtained from the tangent of base shear-displacement curve before and after the earthquake. For this purpose, Dipasquale and Cakmak [36] proposed a procedure based on the variation of the fundamental structural period.

In this procedure, the duration of the excitation is divided into $n_{\text {wind }}$ non-overlapping time windows of width $s_{i}$ seconds. The first window can be made small enough, so that $\left(T_{0}\right)_{1}$ is equal to the fundamental period of the linear oscillation of the structure before the earthquake, $T_{\text {initial }}$. When the record time history is long enough so that the vibration is decreased due to strong motion by the end of the record, the estimate of $\left(T_{0}\right)$ corresponding to the last window, $\left(T_{0}\right)_{n \text { wind }}$, can be assumed to be equal to the fundamental period of the linear vibration after the earthquake, $T_{f}$ [36].

The Bayesian approach can be used to estimate the unknown parameters; more importantly, it provides 
a procedure for incorporating prior knowledge into the observed data to obtain a balanced estimation. By considering the correction term to be a linear function with respect to $\theta$ in order to construct the closedform solution, the model, according to Eq. (1), can be expressed as follows:

$$
\begin{aligned}
\Delta \mathbf{D I} & =\mathrm{DI}(\mathbf{x}, \boldsymbol{\theta}, \sigma)-\widehat{\mathrm{DI}}(\mathbf{x})=\sum_{m=1}^{p} \theta_{m} h_{m}(\mathbf{x})+\sigma \cdot \varepsilon \\
& =\mathbf{H} \theta+\sigma \varepsilon,
\end{aligned}
$$

where $\boldsymbol{\Delta} \mathbf{D I}$ is the $n \times 1$ vector, $\mathbf{H}$ is the $n \times p$ matrix of known regressors, and $\varepsilon$ is the $n \times 1$ vector of independent random variables. In this case, expanding the matrices of Eq. (7) for $n$ set of observed data can be written as follows:

$$
\left[\begin{array}{c}
\Delta D I_{1} \\
\cdot \\
\dot{D} I_{i} \\
\cdot \\
\cdot \dot{D} I_{n}
\end{array}\right]=\left[\begin{array}{c}
1\left(\frac{T_{0}^{2}}{T_{f}{ }^{2}}\right)_{1} \\
\cdot \cdot \\
1\left(\frac{T_{0}^{2}}{T_{f}{ }^{2}}\right)_{i} \\
\cdot \cdot \\
1\left(\frac{T_{0}^{2}}{T_{f}{ }^{2}}\right)_{n}
\end{array}\right]\left[\begin{array}{c}
\theta_{1} \\
\theta_{2}
\end{array}\right]+\sigma \cdot\left[\begin{array}{c}
\varepsilon_{1} \\
\cdot \\
\cdot \\
\varepsilon_{i} \\
\cdot \\
\cdot \\
\varepsilon_{n}
\end{array}\right]
$$

where $\Delta \mathrm{DI}_{i}=\mathrm{DI}_{i}-\widehat{\mathrm{DI}}\left(x_{i}\right)$ represents the difference between the $i$ th observed and estimated DI of the deterministic model at $x_{i}$. Under the normality assumption on $\varepsilon$, the marginal posterior distribution of $\theta$ is a multivariate $t$ distribution, $t_{p} \sim\left[\mathbf{M}_{\theta}, s^{2}\left(\mathbf{H}^{\prime} \mathbf{H}\right)^{-1}, \beta\right]$. The mean of $\theta, \mathbf{M}_{\theta}$, and its covariance matrix, $\sum \cdot \theta \theta$, are [30]:

$$
\begin{aligned}
& M_{\theta}=\left(\mathbf{H}^{\prime} \mathbf{H}\right)^{-1} \mathbf{H}^{\prime} \Delta \mathbf{D I}, \\
& \sum_{\theta \theta}=\beta \mathrm{s}^{2}\left(\mathbf{H}^{\prime} \mathbf{H}\right)^{-1} /(\beta-2),
\end{aligned}
$$

where:

$$
\begin{aligned}
& s^{2}=\frac{1}{\beta}\left(\Delta \mathbf{D I}-\mathbf{H M}_{\theta}\right)^{\prime}\left(\Delta \mathbf{D I}-\mathbf{H} \mathbf{M}_{\theta}\right), \\
& \beta=n-p .
\end{aligned}
$$

In addition, the mean and variance of $\sigma^{2}$ are $\beta s^{2} /(\beta-2)$ and $2 \beta^{2} s^{4} /\left[(\beta-2)^{2}(\beta-4)\right]$, respectively [30]. In this case, the mean vector of $\boldsymbol{\theta}$ is equal to:

$$
\begin{aligned}
\mathbf{M}_{\boldsymbol{\theta}} & =\left[\begin{array}{l}
M_{\theta_{1}} \\
M_{\theta_{2}}
\end{array}\right] \\
& =\left[\begin{array}{c}
\alpha_{1}\left(\alpha_{2} \sum_{i=1}^{n} \Delta D I_{i}-\alpha_{3} \sum_{i=1}^{n} \Delta D I_{i}\left(\frac{T_{0}{ }^{2}}{T_{f}{ }^{2}}\right)_{i}\right) \\
\alpha_{1}\left(-\alpha_{3} \sum_{i=1}^{n} \Delta D I_{i}+n \sum_{i=1}^{n} \Delta D I_{i}\left(\frac{T_{0}{ }^{2}}{T_{f}{ }^{2}}\right)_{i}\right)
\end{array}\right]
\end{aligned}
$$

and the covariance matrix of $\boldsymbol{\theta}$ is:

$$
\sum_{\theta \theta}=\frac{\alpha_{1} \alpha_{4}}{n-4}\left[\begin{array}{cc}
\alpha_{2} & -\alpha_{3} \\
-\alpha_{3} & n
\end{array}\right]
$$

where:

$$
\begin{aligned}
& \alpha_{1}=1 /\left(n \alpha_{2}-\alpha_{3}^{2}\right), \\
& \alpha_{2}=\sum_{i=1}^{n}\left(T_{0}^{4} / T_{f}^{4}\right)_{i}, \\
& \alpha_{3}=\sum_{i=1}^{n}\left(T_{0}^{2} / T_{f}^{2}\right)_{i}, \\
& \alpha_{4}=\sum_{i=1}^{n}\left(\Delta D I_{i}-M_{\theta_{1}}-M_{\theta_{2}}\left(T_{0}{ }^{2} / T_{f}^{2}\right)_{i}\right)^{2} .
\end{aligned}
$$

In addition, the mean value and variance of $\sigma^{2}$ are obtained as follows:

$$
M_{\sigma^{2}}=\frac{\alpha_{4}}{n-4}, \quad \operatorname{Var}_{\sigma^{2}}=\frac{2 \alpha_{4}^{2}}{(n-4)^{2}(n-6)}
$$

The existing damage indices are based on various characteristics such as the number of cycles, stiffness, ductility, and energy [36]. In many studies, a comparison of the effectiveness of different damage indices can be found [12,14], and the Park-Ang model is advised as the preferred damage index. By comparing different damage models with experimental observations, Kunnath and Jenne [37] indicated that DIPA correlated best with laboratory results. The Park-Ang model is the most preferred choice for structural DI in previous studies $[38,39]$. For this reason, in this study, $\mathrm{DI}_{P A}$ was selected as a deterministic damage model to be updated. This model is a combination of ductility and cumulative hysteretic energy as follows $[6,21,40]$ :

$$
D I_{P A}=\frac{d_{m}}{d_{u}}+\frac{\beta \int d E_{h}}{V_{y} d_{u}}
$$

where $d_{m}$ is the maximum response deformation attained during the loading history, $d_{u}$ is the ultimate deformation capacity under static loading, $\beta$ is the constant depending on structural characteristics, $\int d E_{h}$ is incremental absorbed hysteretic energy, and $V_{y}$ is the calculated yield strength [21]. By considering the correction term as per Eq. (6), Eq. (1) is rewritten as:

$$
\mathrm{DI}=\mathrm{DI}_{P A}+\theta_{1}+\frac{T_{0}^{2}}{T_{f}^{2}} \theta_{2}+\sigma . \varepsilon
$$

where the coefficients of this probabilistic damage index is calculated based on the response of the structures to near-fault ground motions. 


\section{Database in updating procedure}

To evaluate the effect of the near-fault earthquake records on the damage of concrete structures, ten different moment-resistant systems in low- and mid-rise frame structures were considered. Plan and elevations of the model frames are shown in Figure 1. These frames were loaded and designed based on Iranian Codes $[41,42]$. The frames were with three- or fivebays. The bay widths of the 2-, 3-, 4-, 6-, and 8storey frames were assumed to be 4 and $5 \mathrm{~m}$ and the height of each storey was assumed to be $3 \mathrm{~m}$. Main period of frames ranged from 0.52 to $0.75 \mathrm{~s}$. Frames A and B on the plan were selected and damage analysis was performed by the IDARC-2D [43]. The program requires specification of member behavior in terms of moment curvature envelopes and an associated hysteretic rule. For each component cross-section, the moment curvature relation is specified as a nonsymmetric tri-linear envelope with three degrading hysteretic parameters. IDARC program included the Park and Ang damage models to provide a measure of the accumulated damage sustained by the components of the structure, each story level, and the entire building.
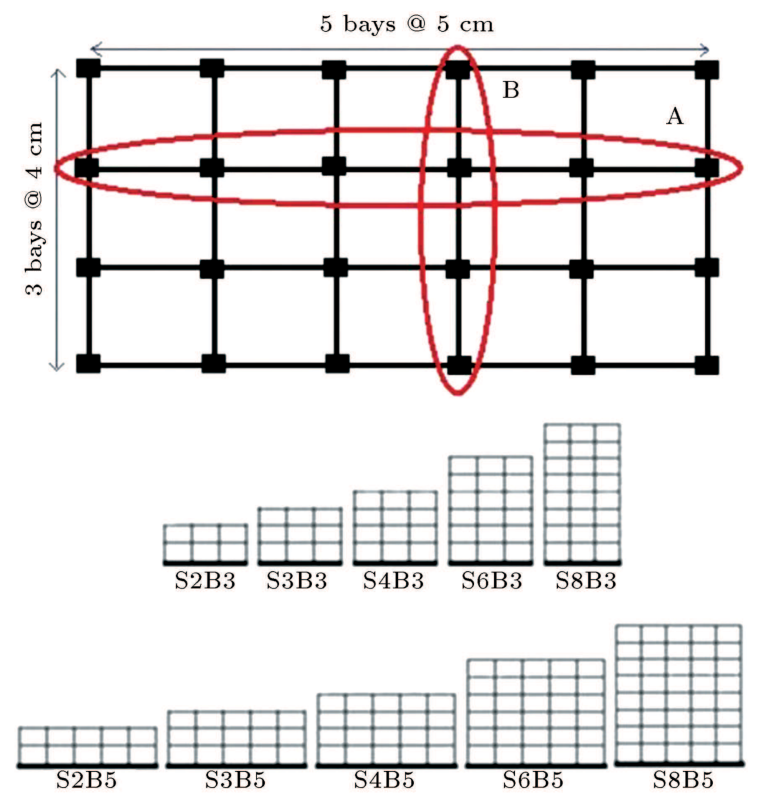

Figure 1. Plan and elevation of the concrete frames.
In near-fault events, sometimes, a large pulse can be seen in the velocity time history of ground motions. When the fault rupture propagates toward the site, the likelihood of pulse-like excitation occurrence increases at near-fault sites. Due to the pulse-like movement, constructive interference of the wave front occurs and seismic energy with large amplitude pulse is released from the rupture [44]. Therefore, the amount of information about structural damage level after these earthquakes can play an important role in the seismic design and evaluation of near-fault structures. Past research has shown that near-fault pulse-like records tend to increase the displacement response of structures relative to non-pulse-like excitations $[45,46]$. These increases in displacement cause variation in DI $[47,48]$. In this study, a set of important near-fault earthquake records was chosen to determine the damage model of near-fault structures. The ground motions were recorded from events with moment magnitude $\left(M_{w}\right)$ ranging from 6.2 to 7.6 and distance from 5 to $15 \mathrm{~km}$. Table 1 shows the characteristics of the selected nearfault pulse-like records. Observed damage data in these events in reinforced structures are used for Bayesian updating of DIPA model. All records were selected from soft soil sites.

\section{Results}

$\mathrm{DI}_{\mathrm{PA}}$ in different frames was calculated using nonlinear time-history analysis under near-fault earthquake records. The effects of the vertical component were considered in dynamic analysis of structures. Figure 2 shows $\mathrm{DI}_{\mathrm{PA}}$ in different events for ten different frames. Maximum damage is related to Chi-Chi earthquake that has the highest Peak Ground Acceleration (PGA), and minimum damage is related to the Northridge earthquake with the minimum PGA.

Figure 3 indicates the variation of the structural period as an example of a four-storey frame in the Kobe earthquake. Figure 4 shows the square ratio of the initial period to the final period of different frames using time-history analysis under different near-fault events. This figure illustrates that this ratio is lower in severe events than moderate events.

The variation of the square ratio of initial to

Table 1. Characteristics of the selected records.

\begin{tabular}{cccccccc}
\hline Event name & $\begin{array}{c}\text { Event date } \\
\text { Y-M-D }\end{array}$ & Latitude & Longitude & $\boldsymbol{M}_{\boldsymbol{w}}$ & $\begin{array}{c}\text { Depth } \\
(\mathbf{k m})\end{array}$ & $\begin{array}{c}\text { Distance } \\
(\mathbf{k m})\end{array}$ & $\begin{array}{c}\text { PGA } \\
(\mathbf{g})\end{array}$ \\
\hline Northridge, United State & $1994-01-17$ & 34.209 & -118.541 & 6.7 & 18.3 & 8.1 & 0.344 \\
Kobe, Japan & $1995-01-16$ & 34.583 & 135.018 & 6.9 & 22 & 6.7 & 0.693 \\
Chi-Chi, Taiwan & $1999-09-21$ & 23.77 & 120.98 & 7.6 & 8 & 9.8 & 0.902 \\
L'Aquila, Italy & $2009-04-06$ & 42.334 & 13.334 & 6.3 & 8.8 & 4.9 & 0.647 \\
Christchurch, New Zealand & $2011-02-22$ & -43.6 & 172.710 & 6.2 & 5.9 & 10.6 & 0.519 \\
\hline
\end{tabular}



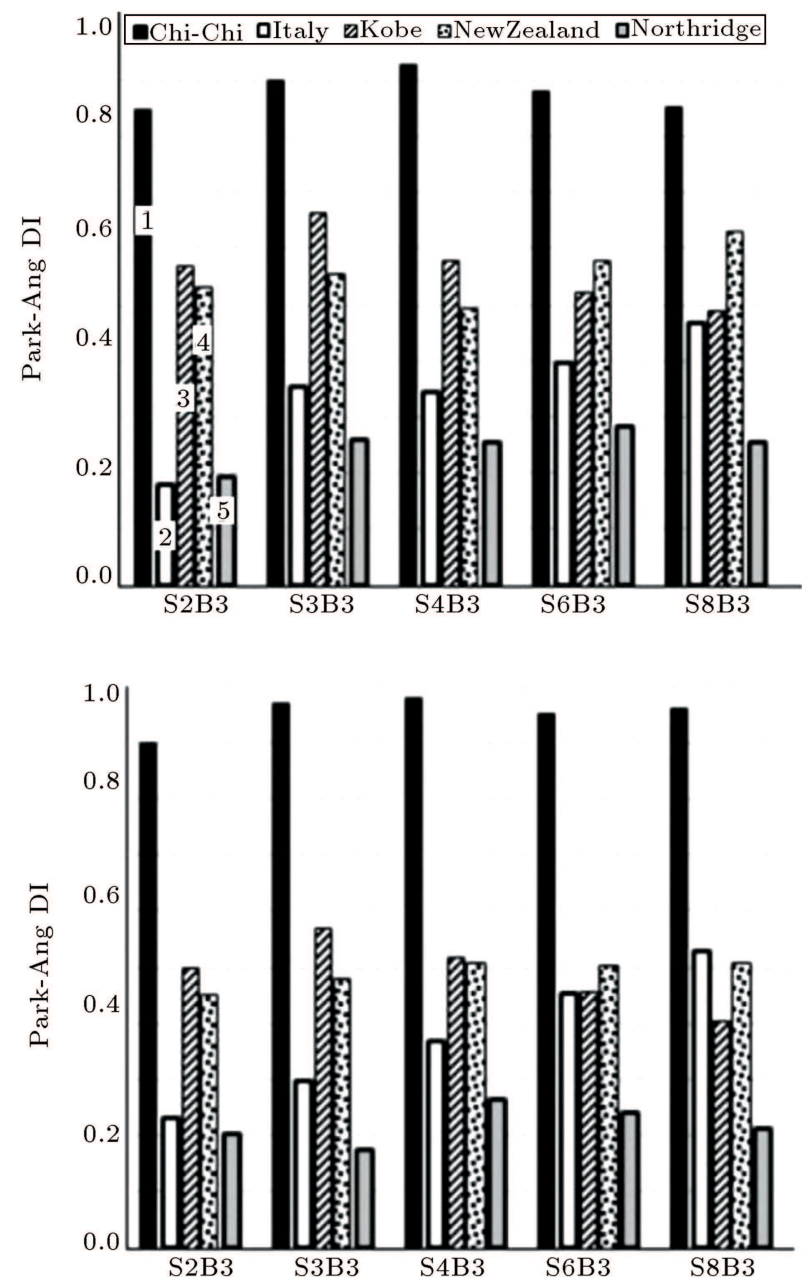

Figure 2. Park-Ang DI in different frames under different events.

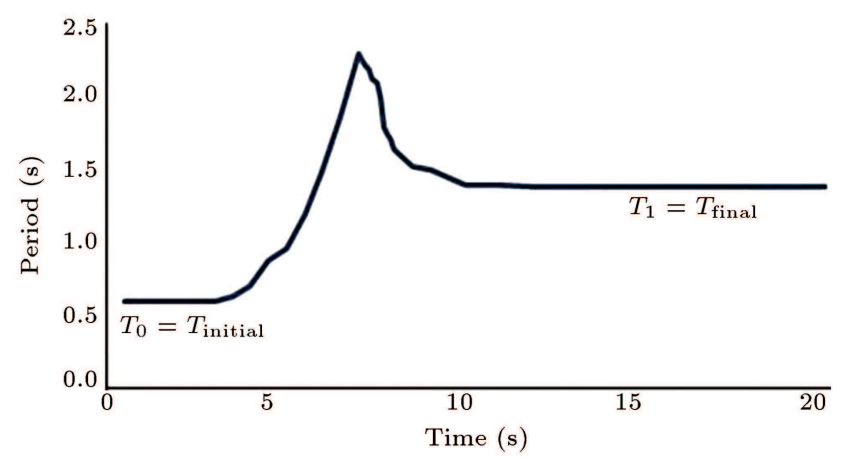

Figure 3. Variation of a structural period in 4-storey structures under Kobe earthquake.

final periods in comparison with $\mathrm{DI}_{\mathrm{PA}}$ in different structures is shown in Figure 5. It is shown that by increasing $\mathrm{DI}_{\mathrm{PA}}$, the ratio of periods tends to decrease. The deterministic Park-Ang model was updated using obsereved damage data from previous near-field earthquakes. Different traces in Figure 6 demonstrate the density of structural damage based on observational
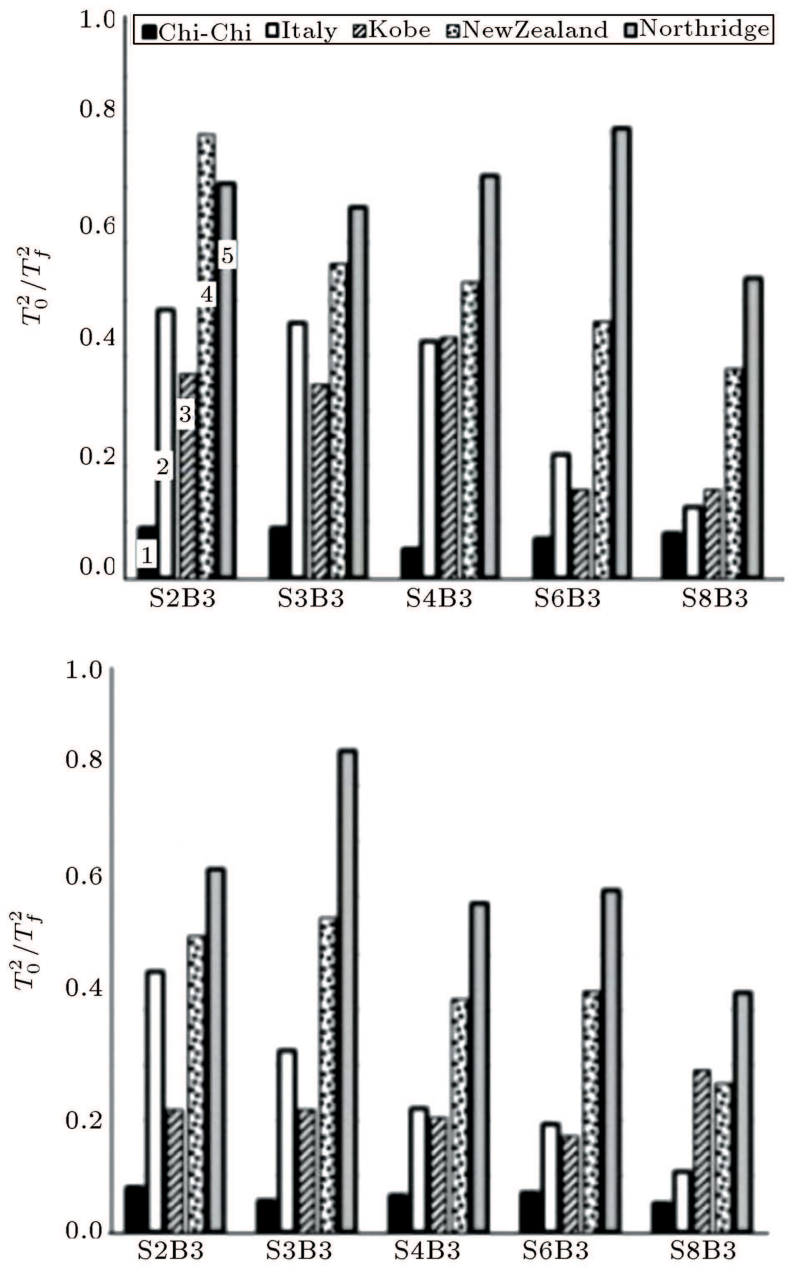

Figure 4. Variation of the square of initial period to final period for different earthquakes.

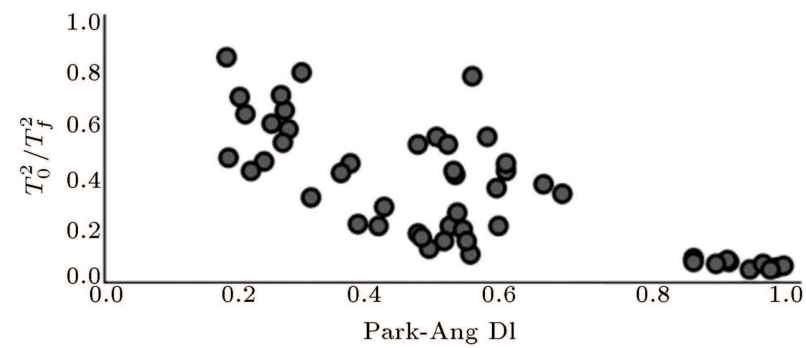

Figure 5. Variation of the square of initial period to final period in terms of Park-Ang DI.

data $\left(\mathrm{DI}_{i}\right)$ in $\mathrm{RC}$ structures under different events, used here to update $\mathrm{DI}_{\mathrm{PA}}$ [49-53]. Moreover, Figure 7 shows the cumulative probability of $\mathrm{DI}_{i}$ at five different events.

Using the Bayesian procedure based on the estimated $\mathrm{DI}_{\mathrm{PA}}$ in different structures and observed damage $\mathrm{DI}_{i}$ in the mentioned event, the damage model of Park-Ang was updated. Table 2 lists the estimated values of the unknown parameters of the damage model in the updating procedure. This probabilistic model 

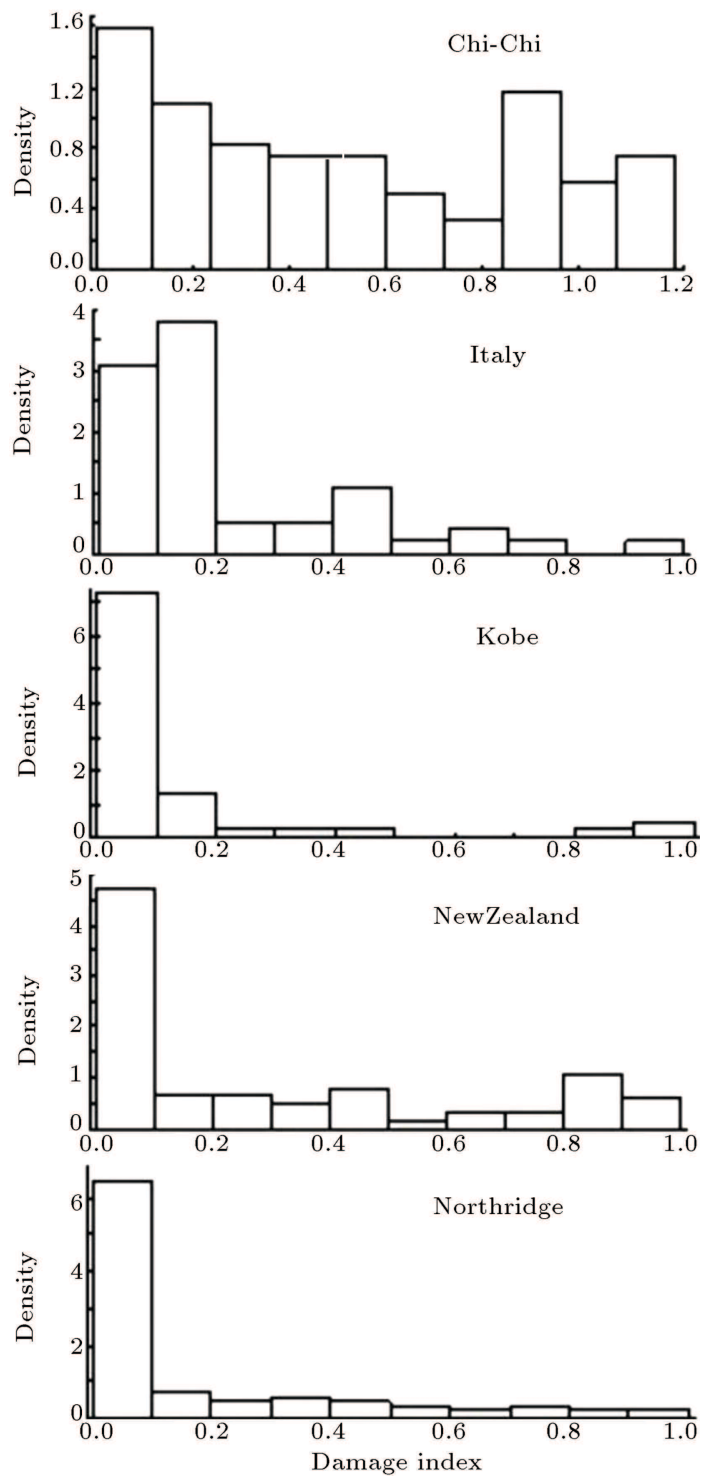

Figure 6. Observational density of damage under different events.

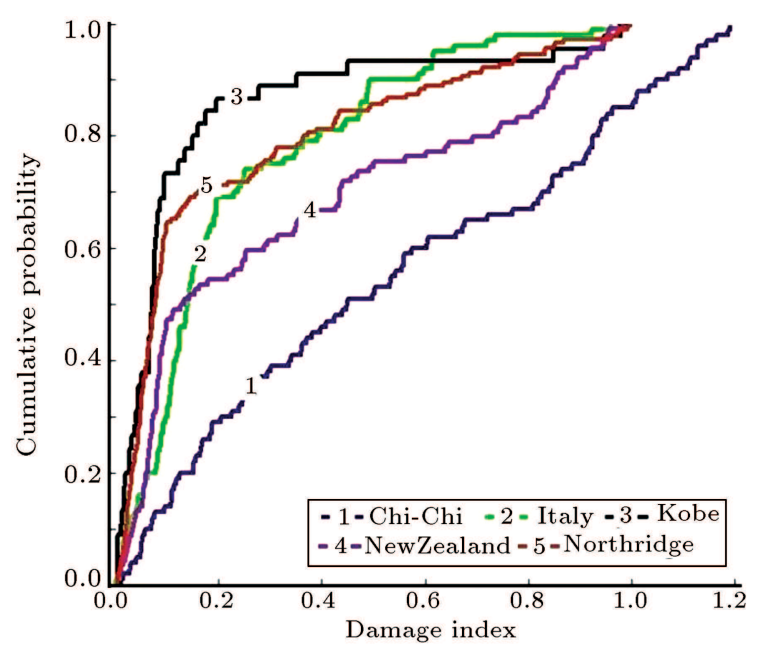

Figure 7. Cumulative probability of damage in different events. identifies the modified parameter affecting the damage of the structure. For the probabilistic DI model, the mean prediction is:

$$
(\mathrm{DI})_{\text {mean }}=\mathrm{DI}_{\mathrm{P} A}-0.29+0.38 \frac{T_{0}^{2}}{T_{f}^{2}}+0.09 . \varepsilon
$$

where $\varepsilon$ is a normal random variable with zero mean and unit variance. According to the mean value and standard deviation of coefficients from Table 2, we have:

$$
-0.314 \leq \theta_{1} \leq-0.266, \quad 0.324 \leq \theta_{2} \leq 0.436 .
$$

With regard to Eq. (15), neglecting the term $\varepsilon$, the difference between the proposed DI and Park-Ang DI depends on the relationship between $\frac{T_{0}}{T_{f}}$ and $\sqrt{\frac{-\theta_{1}}{\theta_{2}}}$. Based on Table 2 and Eq. (16), according to the value of $\frac{T_{0}}{T_{f}}$, we have the following cases:

$$
\begin{aligned}
& \text { If } \frac{\mathrm{T}_{0}}{\mathrm{~T}_{\mathrm{f}}}>0.984 \text {, then } \mathrm{DI}>\mathrm{DI}_{\mathrm{PA}}, \\
& \text { If } 0.781 \leq \frac{\mathrm{T}_{0}}{\mathrm{~T}_{\mathrm{f}}} \leq 0.984 \text {, then } \mathrm{DI}=\mathrm{DI}_{\mathrm{PA}} \text {, } \\
& \text { Else if } \frac{\mathrm{T}_{0}}{\mathrm{~T}_{\mathrm{f}}}<0.781, \text { then } \mathrm{DI}<\mathrm{DI}_{\mathrm{PA}} .
\end{aligned}
$$

Eq. (17) shows the comparison of the median value of the proposed probabilistic DI model with the Park-Ang model, where $\varepsilon$ is equal to zero. In this case, if the ratio of the initial to the final periods is between $0.781-0.984$, then $\mathrm{DI}_{\mathrm{PA}}$ gives a good approximation of the structural damage for near-fault events. For ratios of less than 0.781 or more than 0.984 , compared to the proposed $\mathrm{DI}, \mathrm{DI}_{P A}$ gives higher and lower values of damage to frames, respectively. The relationship between the proposed damage index and Park-Ang damage index with respect to $\frac{T_{0}}{T_{f}}$ is shown in Figure 8 .

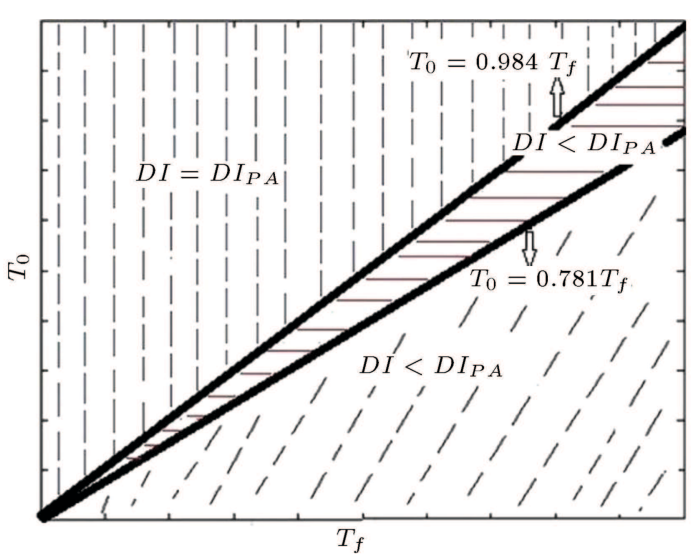

Figure 8. Relationship between the proposed DI and Park-Ang DI with respect to $\frac{T_{0}}{T_{f}}$. 
Table 2. Unknown parameters in damage model.

\begin{tabular}{cccccc}
\hline \multirow{2}{*}{ Coefficients } & Mean & Standard deviation & \multicolumn{2}{c}{ Correlation coefficient } \\
\cline { 4 - 6 } & & & $\boldsymbol{\theta}_{\mathbf{1}}$ & $\boldsymbol{\theta}_{\mathbf{2}}$ & $\boldsymbol{\sigma}$ \\
\hline$\theta_{1}$ & -0.29 & 0.024 & 1 & -0.84 & 0.003 \\
$\theta_{2}$ & 0.38 & 0.056 & -0.84 & 1 & -0.005 \\
$\sigma$ & 0.09 & 0.004 & 0.003 & -0.005 & 1 \\
\hline
\end{tabular}
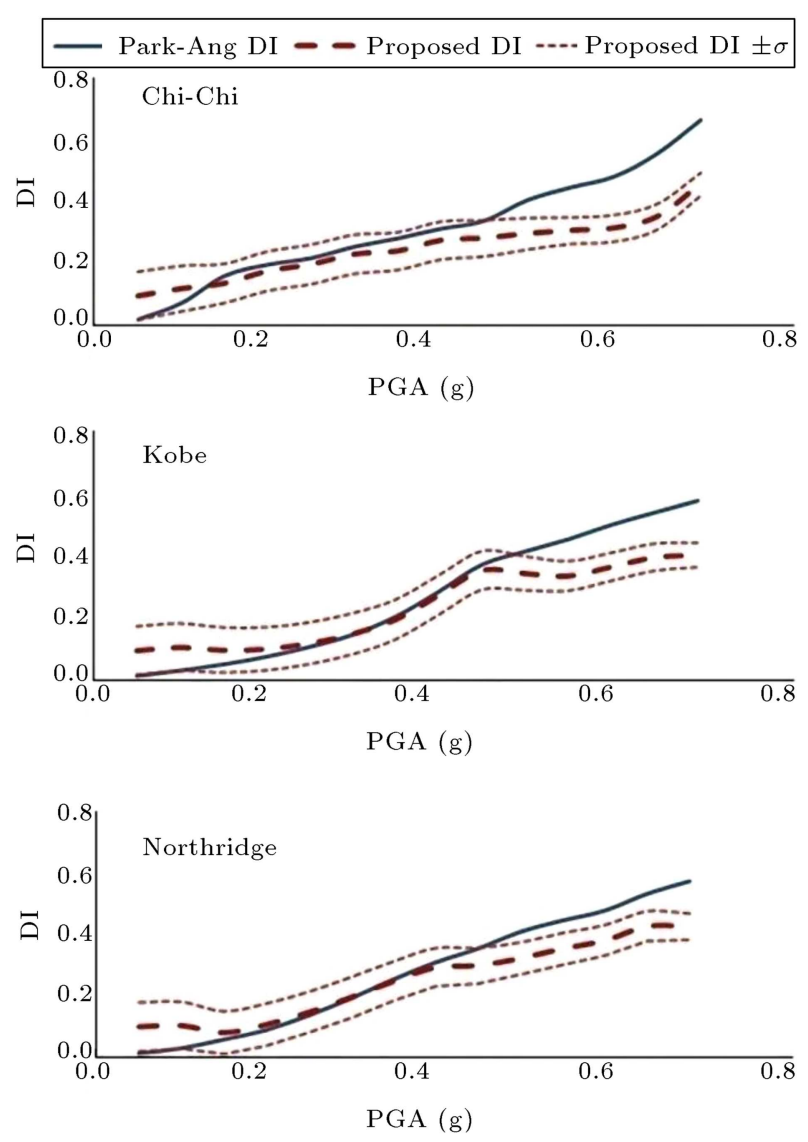

Figure 9. Comparison of the proposed DI with Park-Ang one in the four-storey frame under (a) Chi-Chi, (b) Kobe, and (c) Northridge ground motions.

Figure 9 shows the DI of Park-Ang model with the proposed one as a function of PGA, for Northridge, Kobe, and Chi-Chi earthquakes. This figure compares the two calculated different DIs using a nonlinear dynamic analysis under a multiplied scale of the earthquakes in the 4-storey frame. It is observed that at low and high values of $\mathrm{PGA}, \mathrm{DI}_{P A}$ gives lower and higher damage values for frames under near-fault ground motions. This is due to the fact that the correction term causes increment and decrement of $\mathrm{DI}_{\mathrm{PA}}$ in low and high values of intensity measures, respectively. The effect of the standard deviation in a probabilistic view of damage model is shown.

Table 3 shows the correlation between $\mathrm{DI}_{\mathrm{PA}}$ and the proposed one that corresponds to ten different frames under five different pulse-like ground motions. The correlation of the proposed DI with the Park-Ang damage indices is considered to be satisfactory, owing to the values it provides for correlation coefficient $R^{2}$ between 0.76 and 0.92 , with the larger correlation being at the severe damage level. Furthermore, Figure 10 shows these comparisons at different ranges of damage level using the simplest linear relation. At the moderate damage level, the slope of linear relation is close to unity, meaning a higher level of correlation.

\section{Conclusions and discussions}

This study presented a Bayesian statistical analysis procedure for updating existing damage models. As building damage data from the past ground motions have become increasingly available, these observed data need to be combined with past existing damage models to construct new damage models that are more robust. The Bayesian approach is an effective one that allows for the combination of knowledge of past models with the observed damage data. The formats of the past models were used to estimate the prior estimations of damage in the Bayesian analysis. Data on building damage in near-fault pulse-like earthquakes were used to estimate the likelihood functions.

The Bayesian procedure for damage model updating was illustrated using the damage data on reinforced concrete frame buildings from the Northridge, Kobe, Chi-Chi, L'Aquila, and Christchurch earthquakes. In

Table 3. Correlation between the proposed and Park-Ang DIs in different range of damage.

\begin{tabular}{cccc}
\hline Damage state & Damage index range & Proposed DI & $\boldsymbol{R}^{\mathbf{2}}$ \\
\hline Slight & $<0.1$ & $0.32 \mathrm{DI}_{\mathrm{PA}}+0.075$ & 0.76 \\
Minor and moderate & $0.1-0.4$ & $0.93 \mathrm{DI}_{\mathrm{PA}}+0.011$ & 0.87 \\
Severe and collapse & $>0.4$ & $0.75 \mathrm{DI}_{\mathrm{PA}}-0.03$ & 0.92 \\
\hline
\end{tabular}



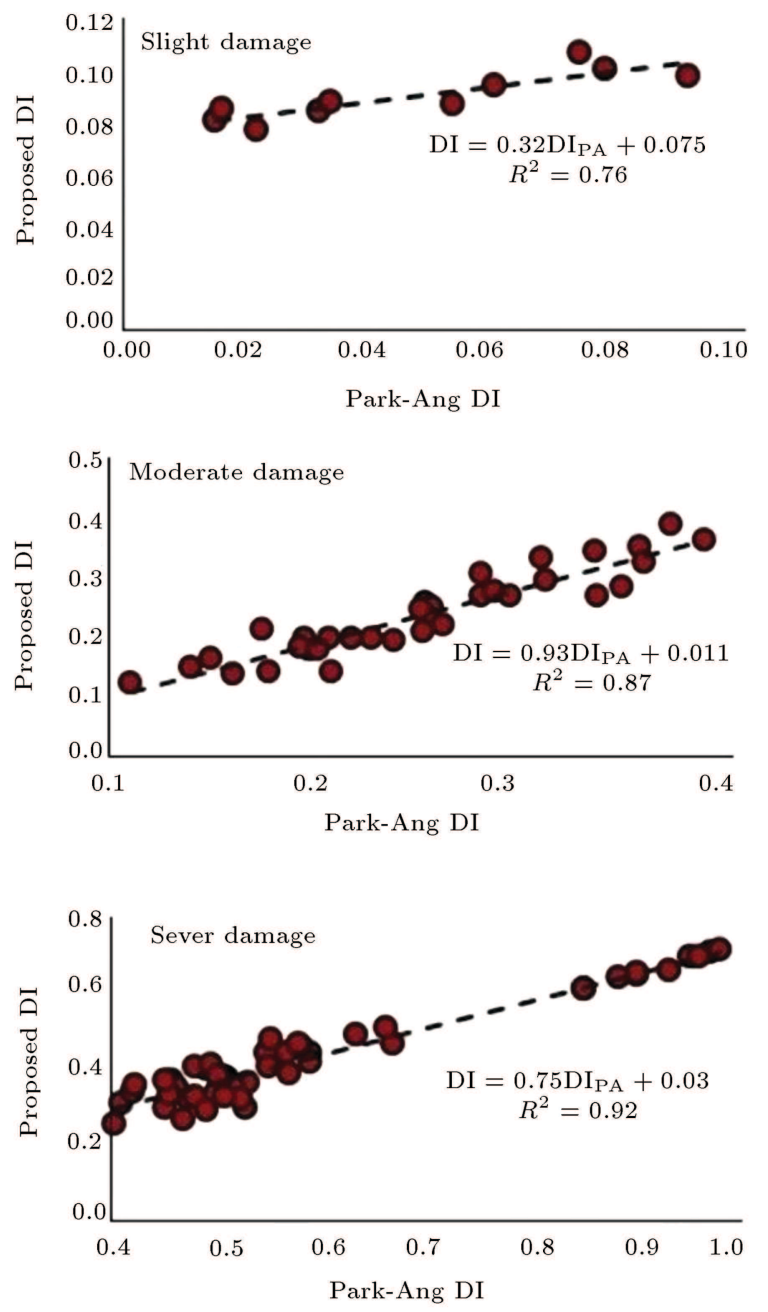

Figure 10. Correlations between the proposed DI and Park-Ang one in different damage levels.

this study, the Park-Ang damage model was considered as the existing deterministic model.

In addition, statistical uncertainty was ignored in the existing damage models, but was not disregarded in the damage analysis. The DI of the RC frames was combined with the damage data of RC structures in near-fault earthquakes so that an updated probabilistic damage model for RC structures was presented. The linear combination of the contributions of damage of the extreme deformation and dissipated energy was the main assumption used in the Park-Ang damage model $[12,54]$. Hence, in this study, the correction term based on the stiffness before and after the loading, which is a more consistent indicator of damage, was added to the Park-Ang damage model. The coefficient of this term, which is based on the concept of the final softening damage index, was calculated using the structural damage in near-fault earthquakes. The results indicate that in low and high values of damage, $\mathrm{DI}_{\mathrm{PA}}$ gives lower and higher damage values for frames in near-fault ground motions. The updated damage model can give useful information concerning the expected performance of a structure at the nearfault sites.

\section{Acknowledgments}

The authors would like to thank anonymous reviewers for comments which helped to improve the manuscript.

\section{References}

1. Paal, S., Jeon, J., Brilakis, I. and DesRoches, R. "Automated damage index estimation of reinforced concrete columns for post-earthquake evaluations", Journal of Structural Engineering, 141(9), pp. 1-13 (2015).

2. Krawinkler, H. and Zohrei, M. "Cumulative damage in steel structures subjected to earthquake ground motion", Computers and Structures, 16(1-4), pp. 531541 (1983).

3. Park, Y.J. and Ang, A.H. "Mechanistic seismic damage model for reinforced concrete", Journal of Structural Engineering, ASCE, 111(4), pp. $722-739$ (1985).

4. Mohammadjalal, M.A. and Estekanchi, H.E. "Application of damage spectra as seismic intensity measures in endurance time method for steel moment-resisting frames", Scientia Iranica, 24(1), pp. 53-64 (2017).

5. Cao, V.V. and Ronagh, H.R. " Correlation between seismic parameters of far-fault motions and damage indices of low-rise reinforced concrete frames", Soil Dynamics and Earthquake Engineering, 66(1), pp. 102-112 (2014).

6. Golafshani, A.A., Tabeshpour, M.R., and Bakhshi, A. "Vulnerability and damage analysis of existing buildings", Asian Journal of Civil Engineering, 6(12), pp. 85-100 (2005).

7. Colombo, A. and Negro, P. "A damage index of generalised applicability", Engineering Structures, 27(8), pp. 1164-1174 (2005).

8. Cao, V.V., Ronagh, H.R., Ashraf, M., and Baji, H. "A new damage index for reinforced concrete structures", Earthquakes and Structures, 6(6), pp. 581-609 (2014).

9. Banon, H. and Veneziano, D. "Seismic safety of reinforced concrete members and structures", Earthquake Engineering and Structural Dynamics, 10(2), pp. 179193 (1982).

10. Banon, H., Biggs, J.M., and Irvine, H.M. "Seismic damage in reinforced concrete frames", Journal of the Structural Division, 107(9), pp. 1713-1729 (1981).

11. Roufaiel, M.S.L. and Meyer, C. "Analytical modelling of hysteretic behavior of R/C frames", Journal of the Structural Engineering, 113(3), pp. 429-444 (1987).

12. Ghobarah, A., Abou-Elfath, H. and Biddah, A. "Response base damage assessment of structures", Earthquake Engineering and Structural Dynamics, 28(1), pp. 79-104 (1999). 
13. Powell, G.H. and Allahabadi, R. "Seismic damage prediction by deterministic methods: Concepts and procedures", Earthquake Engineering and Structural Dynamics, 16(5), pp. 719-734 (1988).

14. Fajfar, P. "Equivalent ductility factors, taking into account low-cycle fatigue", Earthquake Engineering and Structural Dynamics, 21(10), pp. 837-848 (1992).

15. Padilla, D. and Rodriguez, M. "A damage index for the seismic analysis of reinforced concrete members", Journal of Earthquake Engineering, 13(3), pp. 364-383 (2009).

16. Karantoni, F.V., Fardis, M.N., Vintzeleou, E., and Harisis, A. "Effectiveness of seismic strengthening measures", IABSE Symposium on Structural Preservation of the Architectural Heritage, 70, pp. 548-556 (1993).

17. Ghobarah, A. and Aly, N.M. "Seismic reliability assessment of existing reinforced concrete buildings", Journal of Earthquake Engineering, 2(4), pp. 569-592 (1998).

18. Bozorgnia, Y. and Bertero, V.V. "Improved shaking and damage parameters for post-earthquake applications", Proceedings, SMIP01 Seminar on Utilization of Strong-Motion Data, Los Angeles, pp. 1-22 (2001).

19. Yüksel, E. and Sürmeli, M. "Failure analysis of onestory precast structures for near-fault and far-fault strong ground motions", Bulletin of Earthquake Engineering, 8(4), pp. 937-953 (2010).

20. Bassam, A., Iranmanesh, A., and Ansari, F. "A simple quantitative approach for post earthquake damage assessment of flexure dominant reinforced concrete bridges", Journal of Engineering Structures, 33(12), pp. 3218-3225 (2011).

21. Ghosh, S., Datta, D., and Katakdhond, A.A. "Estimation of the Park-Ang damage index for planar multistorey frames using equivalent single-degree systems", Journal of Engineering Structures, 33(9), pp. 25092524 (2011).

22. Arjomandi, K., Estekanchi, H., and Vafai, A. "Correlation between structural performance levels and damage indices in steel frames subjected to earthquakes", Scientia Iranica, 16(2), pp. 147-155 (2009).

23. Zhang, R. and Mahadevan, S. "Model uncertainty and Bayesian updating in reliability-based inspection", Structural Safety, 22(2), pp. 145-160 (2000).

24. Wang, M. and Takada, T. "A Bayesian framework for prediction of seismic ground motion", Bulletin of the Seismological Society of America, 99(4), pp. 2348-2364 (2009).

25. Assareh, H., Noorossana, R., Mohammadi, M., and Mengersen, K. "Bayesian multiple change-point estimation of Poisson rates in control charts", Scientia Iranica, 23(1), pp. 316-329 (2016).

26. Zhu, L. "Probabilistic drift capacity models for reinforced concrete columns", Master Thesis, University of British Columbia (2005).
27. O'Hagan, A., Rudas, T., Gasparini, M., Rogantin, M., Sobel, M., and Goldreich, O. "The Bayesian approach to statistics", Handbook of Probability: Theory and Applications, Part II: Probability Theory in Research Methodology (2008).

28. Iervolino, I. and Cornell, C.A. "Probability of occurrence of velocity pulses in near-source ground motions", Bulletin of the Seismological Society of America, 98(5), pp. 2262-2277 (2008).

29. Bray, J.D., Rodriguez, A. and Gillie J.L. "Design ground motions near active faults", Bulletin of the New Zealand Society for Earthquake Engineering, 42(1), pp. 1-8 (2009).

30. Gardoni, P. "Probabilistic models and fragility estimates for bridge components and systems", Ph.D. Dissertation, Department of Civil and Environmental Engineering, University of California, Berkeley (2002).

31. Gardoni, P., Der Kiureghian, A. and Mosalam, K.M. "Probabilistic capacity models and fragility estimates for reinforced concrete columns based on experimental observations", Journal of Engineering Mechanics, 128(10), pp. 1024-1038 (2002).

32. Dipasquale, E. and Cakmak, A.S. "On the relation between local and global damage indices", Technical Report NCEER-89-0034, State University of New York at Buffalo (1989).

33. Otani, S., Cheung, V.W.T., and Lai, S.S. "Behaviour and analytical models of reinforced concrete columns under biaxial earthquake loads", Proceedings, 3rd Canadian Conference on Earthquake Engineering, Montreal, P.Q., pp. 1141-1168 (1979).

34. Sozen, M.A. "Review of earthquake response of reinforced concrete buildings with a view to drift control", State-of-the-Art in Earthquake Engineering, Turkish National Committee on Earthquake Engineering Istanbul, Turkey, pp. 383-418 (1981).

35. Dipasquale, E. and Cakmak, A.S. "Detection and assessment of seismic structural damage", Technical Report NCEER-87-0015, State University of New York at Buffalo (1987).

36. Sadeghi, K. "Energy based structural damage index based on nonlinear numerical simulation of structures subjected to oriented lateral cyclic loading", International Journal of Civil Engineering, 9(3), pp. 155-164 (2011).

37. Kunnath, S.K. and Jenne, C. "Seismic damage assessment of inelastic R.C structures", Proceedings of the 5th US National Conference on Earthquake Engineering (1994).

38. Park, Y.J., Reinhorn, A., and Kunnath, S.K. "Inelastic damage analysis of reinforced concrete wall frame structures", Report NCEER 87 0008, NCEER/SUNY/Buffalo (1987).

39. Van de Lindt, J. "Damage-based seismic reliability concept for wood frame structures", Journal of Structural Engineering, ASCE, 131(4), pp. 668-675 (2005). 
40. Karamodin, A. Irani, F., and Baghban, A. "Effectiveness of a fuzzy controller on the damage index of nonlinear benchmark buildings", Scientia Iranica, 19(1), pp. 1-10 (2012).

41. Standard No. 2800-5, Iranian Code of Practice for Seismic Resistant Design of Buildings, 4rd Revision, Building and Housing Research Center, Iran (2014) (In Persian).

42. Iranian National Building Codes "Part 9- design and construction of R.C. buildings", Building and Housing Research Center, Iran (2013) (In Persian).

43. Kunnath, S.K., Reinhorn, A.M. and Lobo, R.F. "IDARC Version 7: A program for the inelastic damage analysis of RC structures", Technical Report, National Center for Earthquake Engineering Research, State University of New York, Buffalo, NY (2010).

44. Liel, A. and Champion, C. "The effect of near-fault directivity on building seismic collapse risk", Earthquake Engineering and Structural Dynamics, 41(10), pp. 1391-1409 (2012).

45. MacRae, G.A., Morrow, D.V., and Roeder, C.W. "Near-fault ground motion effects on simple structures", Journal of Structural Engineering, 127(9), pp. 996-1004 (2001).

46. Akkar, S., Yazgan, U., and Gulkan, P. "Drift estimates in frame buildings subjected to near-fault ground motions", Journal of Structural Engineering, 131(7), pp. 1014-1024 (2005).

47. Tothong, P. and Cornell, C.A. "Structural performance assessment under near-source pulse-like ground motions using advanced ground motion intensity measures", Earthquake Engineering and Structural Dynamics, 37(7), pp. 1013-1037 (2008).

48. Baker, J.W. and Cornell, C.A. "Vector-valued intensity measures for pulse-like near-fault ground motions", Engineering Structures, 30(4), pp. 1048-1057 (2008).

49. Blakeborough, A., Merriman, P.A., and Williams, M.S. "The Northridge, California earthquake of 17 January 1994: A field Report By EEFIT", Earthquake
Engineering Field Investigation Team, London, p. 196 (1997).

50. Tsai, K.C., Hsiao, Ch.P., and Bruneau, M. "Overview of building damage in 921 Chi-Chi earthquake", Earthquake Engineering and Engineering Seismology, 2(1), pp. 93-108 (2000).

51. Okada, T. "Needs to evaluate real seismic performance of buildings- lessons from the 1995 Hyogoken-Nambu earthquake", The EERC-CUREe Symposium in Honor of Vitelmo V. Bertero, Berkeley, California (1997).

52. Liel, A.B. and Lynch, K.P. "Vulnerability of reinforced concrete frame buildings and their occupants in the 2009 L'Aquila, Italy earthquake", Natural Hazards Review, 13(1), pp. 11-23 (2012).

53. Kam, W.Y., Pampanin, S., and Elwood, K. "Seismic performance of reinforced concrete buildings in the 22 February Christchurch (Lyttelton) earthquake", Bulletin of The New Zealand Society For Earthquake Engineering, 44(4), pp. 239-278 (2011).

54. He, Y.B., Deng, P., Zhang, Ch., and Shen, P.Sh., The Modification on the Discreteness of Park-Ang Damage Index Based on Bayesian Methodology, Harbin Institute of Technology, 21(1), pp. 15-38 (2014).

\section{Biographies}

Kowsar Yazdannejad is a PhD Student at the Department of Civil Engineering at University of Kurdistan, Sanandaj, Iran. She received her MSc degree from Road, Housing and Urban Development Research Center, Tehran, Iran, and BSc degree from Tabriz University, Tabriz, Iran, respectively, in 2007 and 2011. Her research interests include uncertainty in engineering and reliability of structures.

Azad Yazdani, PhD, is an Associate Professor at the Department of Civil Engineering, University of Kurdistan, Sanandaj, Iran. His research interests lie in uncertainty analysis and intersection of the general fields of seismology and structural engineering. 